\title{
The integration of sex and gender considerations in health policymaking: a scoping review
}

\author{
Allison Williams ${ }^{*} \mathbb{D}$, Joonsoo Sean Lyeo, Sophie Geffros and Alexander Mouriopoulos
}

\begin{abstract}
While the terms 'sex' and 'gender' represent distinct concepts, their influence may intersect as important determinants of health. Despite their influence in shaping individual health outcomes, there is often inaccuracy and inconsistency in the degree to which sex and gender considerations are integrated in the health policymaking process. This primary aim of this paper is to fill the gap in the current understanding of how sex and gender considerations are integrated in this process. A scoping review methodology was used with the objective of assessing the extent to which sex and gender were considered inclusively and comprehensively in established examples of health policy planning and development. One hundred seventy-five documents from the academic and grey literature were found to meet the inclusion criteria for this scoping review. The authors charted the data from these publications, assessing the ways in which sex and gender were incorporated in their policy development process. Five key findings were ascertained from this review: (1) the terms sex and gender are often used interchangeably; (2) the terms sex and gender are often used with a limited and binary scope; (3) the most inclusive and comprehensive documents included transgender and gender diverse populations; (4) there are significant variations in the degree of inclusivity and comprehensivity of these documents based on geographic distribution; and (5) documents published within the last 5 years were more inclusive than older documents. This paper concludes with an acknowledgment of the limitations of the study design, a summary of the findings, future research directions, and implications for policymakers.
\end{abstract}

Keywords: Gender, Health policy, Inclusivity, Policymaking, Sex

\section{Introduction}

This scoping review is the first of three iterative stages in a wider project following the methodological framework outlined by Day et al. [1], who used this methodology in the development of essential metrics for assessing the integration of sex and gender considerations in health research proposals involving human participants. Rather than assessing sex and gender in human health research proposals, this larger project will apply the aforementioned framework in the development of essential metrics for assessing the integration of sex

\footnotetext{
* Correspondence: awill@mcmaster.ca
} Hamilton, Canada

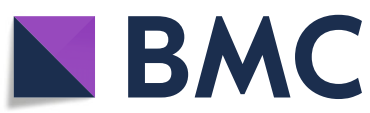

and gender considerations in health policymaking. It should be noted that, in this manuscript, we will be defining a 'policy' as a collection of principles that have been created with the intent of guiding decisions and shaping outcomes. More specifically, we will be defining 'health policy' as a collection of principles that have been created with the intent of guiding decisions specific to shaping health outcomes, broadly defined via the social determinants of health.

As the first of the three iterative stages, the objective of this scoping review was to determine the inclusivity and comprehensiveness of the use of sex and gender in health policymaking. We begin by providing a discussion

(c) The Author(s). 2021 Open Access This article is licensed under a Creative Commons Attribution 4.0 International License, which permits use, sharing, adaptation, distribution and reproduction in any medium or format, as long as you give appropriate credit to the original author(s) and the source, provide a link to the Creative Commons licence, and indicate if changes were made. The images or other third party material in this article are included in the article's Creative Commons licence, unless indicated otherwise in a credit line to the material. If material is not included in the article's Creative Commons licence and your intended use is not permitted by statutory regulation or exceeds the permitted use, you will need to obtain permission directly from the copyright holder. To view a copy of this licence, visit http://creativecommons.org/licenses/by/4.0/ The Creative Commons Public Domain Dedication waiver (http://creativecommons.org/publicdomain/zero/1.0/) applies to the data made available in this article, unless otherwise stated in a credit line to the data. 
specific to the importance of an inclusive and comprehensive understanding of sex and gender in the development and implementation of health policy. This is followed by the methods used in implementing the scoping review. Finally, the results are presented, followed by a conclusion, where next steps are outlined.

\section{Background}

Although the terms 'sex' and 'gender' are frequently used inconsistently and interchangeably, it should be noted that they are not synonymous, and that they represent distinct concepts [2]. The term 'sex' refers to the genetic, physiological, and biological characteristics which have traditionally been used to distinguish males and females. This is in contrast to the term 'gender', which refers to the socially-constructed characteristics which have traditionally been used to distinguish men and women. It should be noted that there is a significant degree of fluidity within the concepts of sex and gender, and that current discourse has come to recognize the complexity of these concepts beyond the binary dichotomies which have traditionally been accepted in the academic literature [2]. For instance, in recognition of the fluidity of sex, there is a growing body of literature acknowledging how variations in chromosomal expression or physiological traits are not always accurately categorized into the male-female binary dichotomy, and may instead be more accurately sorted under the umbrella of 'intersex' variations [3].

While 'sex' and 'gender' represent distinct concepts, their influence may intersect as important, parallel determinants of health [4]. To illustrate, social determinants of health such as income, education and employment, interact with both sex and gender, leading to disparities in health status. Socio-economic factors can contribute to health inequalities, not only between women and men, but among and between different groups of men and women, shaping prospects for health outcomes [4]. For instance, the influence of gender can be seen when discussing family caregivers and caregiver burden [5]. For context, family caregivers are individuals who provide unpaid, informal caregiving services to a care recipient, typically someone in their personal network, with an underlying physical or mental health condition. Much of the literature on family caregivers is limited to the perspectives of cis men and women. That being said, current figures suggest that informal caregiving is predominantly provided by women, in part due to pervasive societal and cultural expectations regarding the role of women in family caregiving [6]. Consequently, women have been reported to spend more time providing informal caregiving, and tend to be more vulnerable to caregiving stressors (i.e. physical strain, psychosocial distress) than men.
Similarly, when looking at family caregiving through the lens of sex, variations can be seen in the experiences of male and female family caregivers [5]. For instance, female caregivers have been reported to experience a greater perception of poor health than their male counterparts. The influence of sex may not only influence the differences in the magnitude of health outcomes between male and female caregivers, but may also influence the type of outcomes displayed. For instance, when examining the sources of caregiver burden, [5] male caregivers tended to experience caregiver burden through low morale and a greater need for social support, whereas female caregivers tended to experience caregiver burden through their relationships with other family members.

Despite their importance in influencing health outcomes, there is often inconsistency in the degree to which sex and gender considerations are integrated in health policymaking. This is highlighted by factors such as: the lack of literature assessing the sex and gender dimensions of policy; the dominance of men in policymaking settings; and the presumed sex-neutral and gender-neutral stance of policies which fail to acknowledge the differential experiences of.

individuals based on their respective sex and gender [7]. This indicates that there may be a gap in our current understanding of how to best integrate sex and gender considerations in health policymaking. Assuming this to be the case, this would suggest a need for tools or strategies to guide policymakers to comprehensively integrate sex and gender in their work.

\section{Methods}

This scoping review followed the methodological framework outlined by Arksey and O'Malley [8]. This particular methodological framework was chosen due to its well-established rigour and effectiveness [9]. Prior to beginning the scoping review, a librarian from McMaster University was consulted to assess its relevance.

Arksey and O'Malley [8] note that scoping reviews are a relatively novel approach relative to the traditional approach of systematic literature reviews. In contrast to systematic literature reviews, which aim to synthesize and aggregate findings on a highly-focused research question, scoping reviews present an overview of broader topics typically encompassing a larger and more diverse body of literature [10]. Taking this distinction into account, the flexibility provided by a scoping review was determined to be invaluable for addressing the volume and diversity of literature, both academic and grey, on the integration of sex and gender considerations in health policymaking. A flow chart summarizing this search process can be found in Fig. 1. Adhering to the methodological framework outlined by Arksey and 


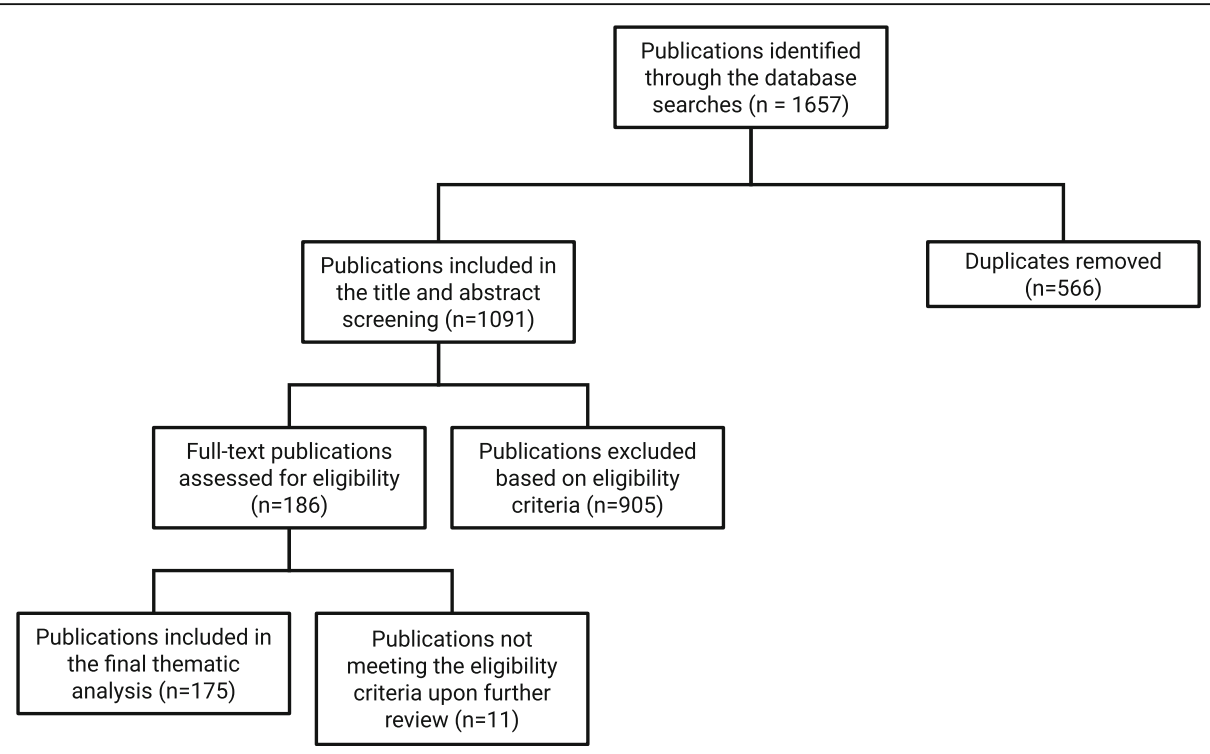

Fig. 1 Flow chart of selection process

O'Malley [8], this scoping review employed the following five-stage model: (i) identifying the research question; (ii) identifying relevant studies; (iii) study selection; (iv) charting the data; and (v) collating, summarizing, and reporting the results.

\section{Stage i: Identifying the research question}

This scoping review was guided by the following research question: 'To what degree has sex and gender been inclusively and comprehensively used in health policymaking'?

\section{Stage ii: Identifying relevant studies}

In an effort to include a wide breadth of literature of relative recency, our scoping review employed a 20-year time span, from January 2000 to June 2020. In order to capture as much of the relevant literature as possible, a broad search strategy was employed in consultation with a McMaster University librarian, inclusive of both the academic and the grey literature. The following nine databases were selected due to their perceived relevance to the research question: Academic OneFile, Canadian Public Documents Collection, EBSCO, LexisNexis, Policy and Society, ProQuest, Scholar Portal Journals, Studies on Women \& Gender Abstracts, Web of Science. An individualized search strategy was tailored to each of these databases, created from some combination of boolean operators and the following 20-sex search terms: 'checklist"', 'female', 'FTM', 'gender', 'genderqueer', 'gender aware*', 'gender divers"', 'gender mainstreaming', 'gender respons"', 'gender sensitiv*', 'intersex', 'male', 'men', 'MTF', 'non-binary', 'polic"', 'policy implementation', 'policy making', 'sex', 'standards development', 'technical standards', 'tool"', 'transgender*', 'transs"', 'two-spirit', and 'women'. The method yielded 1657 results across all databases.

\section{Stage iii: Study selection}

As had been expected, this search strategy picked up a large number of irrelevant studies. A set of inclusion criteria was developed post hoc and then applied to all the citations yielded by this search strategy. Citations were included into the scoping review based on the following criteria: (i) publication date was between January 2000 and June 2020 inclusive; (ii) discussed some sort of metric for assessing the integration of sex and gender considerations in health policymaking; and (iii) was published in the English language. After duplicates were removed from the 1657 citations yielded by the initial search method, the reviewers applied the inclusion criteria to the titles and abstracts of the 1091 remaining citations. This method yielded 186 publications from the initial 1657 results. These publications were divided among the authors and read in full for subsequent stages of the scoping review.

\section{Stage iv: Charting the data}

All four authors participated in extracting and charting the data from the 186 publications [11-178] slated for inclusion. The key findings of these publications were documented on a spreadsheet available to all four authors. The following information was recorded from each publication, as outlined on Fig. 2 below: (i) year of publication; (ii) publication title; (iii) operationalization of the term sex; (iv) inclusivity of the term sex (scored using a five-point Likert scale, with one being least 


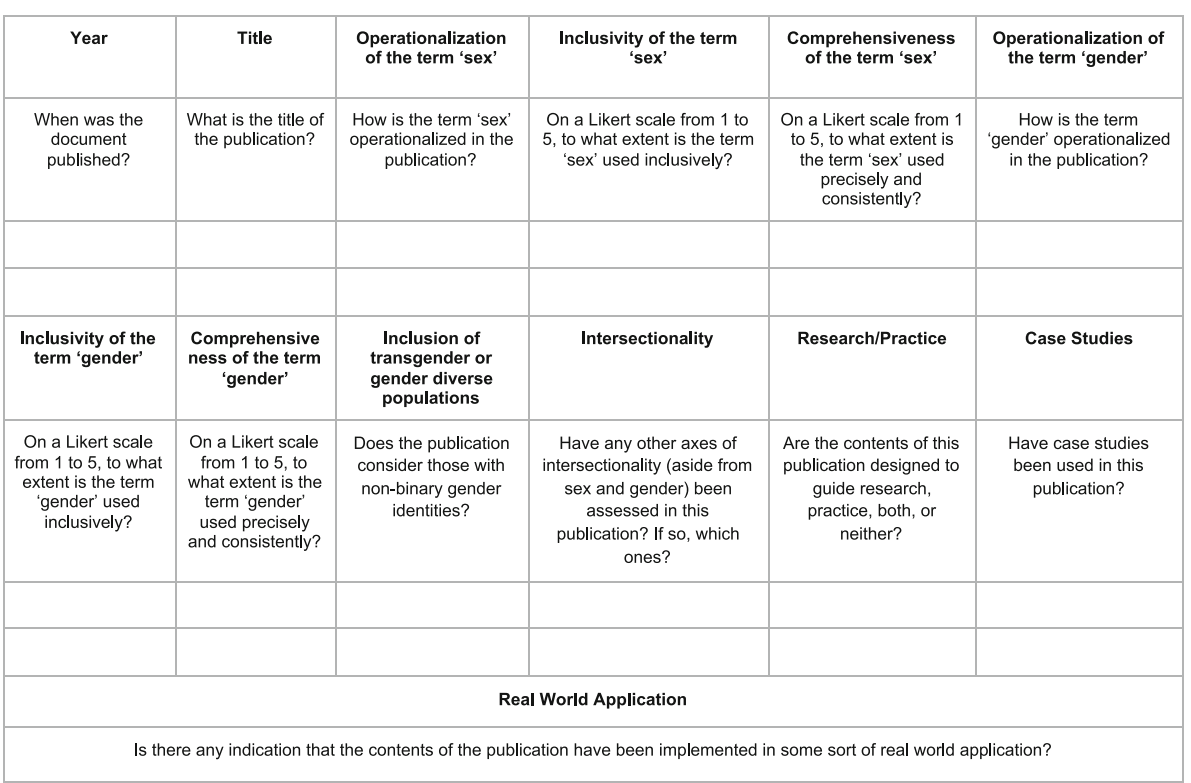

Fig. 2 Categories used for charting the data from articles assessed in the scoping review

inclusive and five being most inclusive); (v) comprehensiveness of the term sex (scored using a five-point Likert scale, with one being least inclusive and five being most inclusive); (vi) operationalization of the term gender; (vii) inclusivity of the term gender (scored using a fivepoint Likert scale, with one being least inclusive and five being most inclusive); (viii) comprehensiveness of the term gender (scored using a five-point Likert scale, with one being least inclusive and five being most inclusive); (ix) inclusion of transgender or gender diverse populations; (x) consideration of other axes of intersectionality; (xi) relevance to research or practice; (xii) use of case studies; (xiii) indication of real world application. These categories have been summarized in Fig. 2. Furthermore, a graphic summary of the publications assessed in this review, as well as their corresponding scores on the aforementioned Likert scales, is provided in the bar graphs shown in Figs. 3, 4, 5, and 6.

In assessing the inclusivity and comprehensiveness of the documents' use of sex and/or gender, attention was paid to if, and how, sex and gender were defined. If they were defined, the authors further determined: if this definition made a meaningful distinction between the terms; if this definition was used consistently, and whether the document recognized diversity within these groups.

As noted, sex and gender inclusivity were assessed using a five-point Likert scale which identified the extent to which documents recognized the existence of intersex and transgender populations, as well as recognition of the diverse experiences of individuals within sex and gender subgroups. Sex and gender comprehensiveness were also assessed using a five-point Likert scale which identified how the documents defined sex and gender, whether the definitions were distinct from each other, and whether these definitions were used comprehensively. The measures assessing comprehensiveness were added after it became apparent that many documents which defined sex and gender in their opening paragraphs as being distinct biopsychosocial phenomena would then go on to use the terms 'man/woman' and 'male/female synonymously. For a document to receive the highest possible ranking on all measures, it would need to be: inclusive of intersex and transgender populations, recognize the diversity within the sex and gender categories used, distinctly and appropriately define sex and gender, and use the terms consistently and at no point synonymously.

Stage v: Collating, summarizing, and reporting the results While reading the full-text publications, 11 books were determined to fall outside of the study inclusion criteria, and were thus excluded from the final analysis. The final sample of 175 publications included both academic and grey literature. Approximately $36.9 \%$ of the publications included in this final sample were peer-reviewed academic articles. The vast majority (approximately 63.1\%) of publications in the final sample were from the grey literature. Approximately $36.9 \%$ of these publications from the grey literature could be described as policy toolkits, intended to provide a rigorous and standardized framework to guide the policymaking of organizations. The remaining $63.1 \%$ could be described as policy papers, intended to contextualize policy issues for non- 


\section{Publications scored by degree of inclusivity of the term 'sex'}

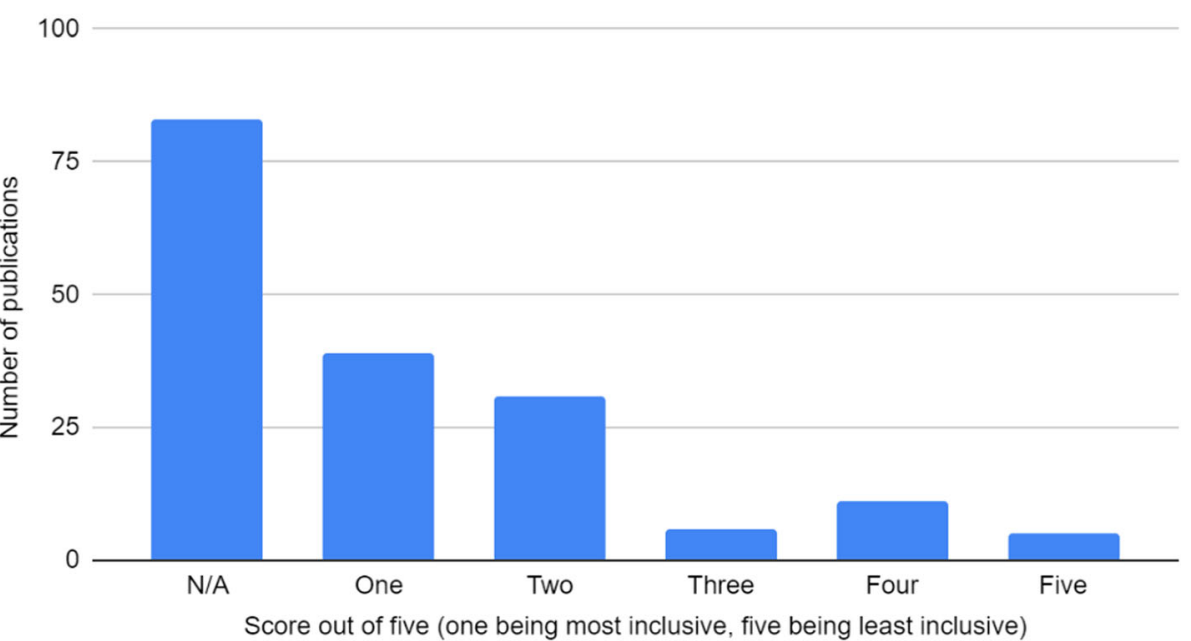

Fig. 3 Publications scored based on their degree of inclusivity of the term 'sex'

academic audiences, highlight current best practices in policy making, and provide broad recommendations to guide the policymaking of organizations. The grey literature was retrieved from a diverse array of geographical contexts, with government documents originating from international organizations, regional agencies, and national governments. The diverse origins of these documents, while unexpected, allowed for the application of a geographic lens to the results of the scoping review. A comprehensive summary of the results of the scoping review are presented below, in the 'Results' section of this paper.

\section{Results}

As illustrated in the flow diagram in Fig. 1, nine databases were searched to extract 186 sources determined to meet the inclusion criteria. Books were removed from the total number of sources, leaving 175 sources. While this is a large number when compared to other knowledge synthesis approaches (i.e. systematic review), the authors choose to conduct a full review of each of these 175 sources. Of the 175 sources included in the scoping review, 43 were policymaking toolkits, 69 were policy or government documents, and 63 were academic peerreviewed articles.

\section{Publications scored by comprehensiveness of the term 'sex'} 100

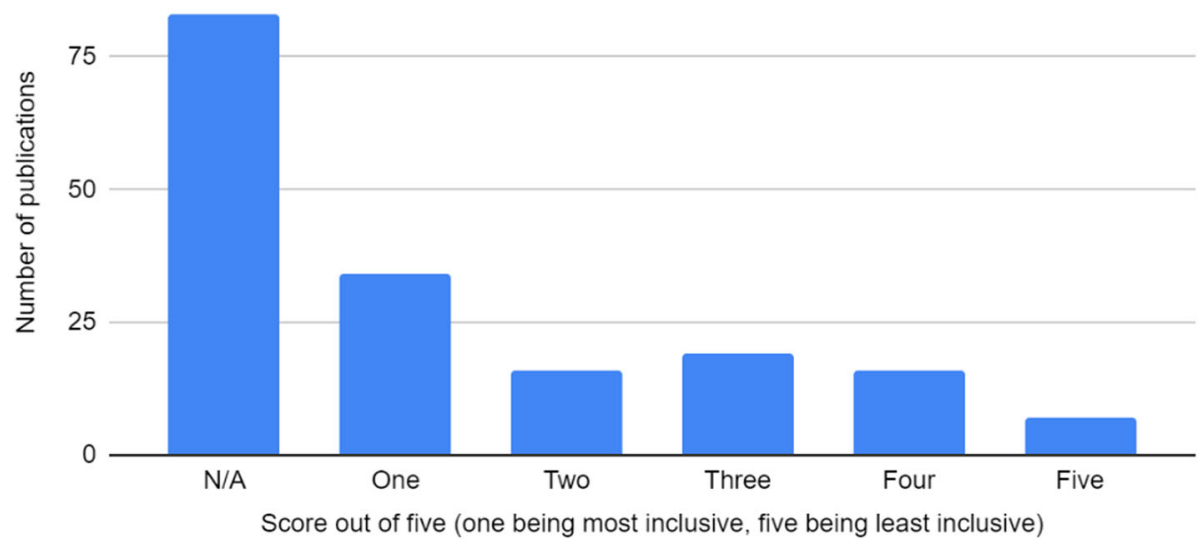

Fig. 4 Publications scored based on their comprehensiveness of the term 'sex' 


\section{Publications scored by degree of inclusivity of the term 'gender'}

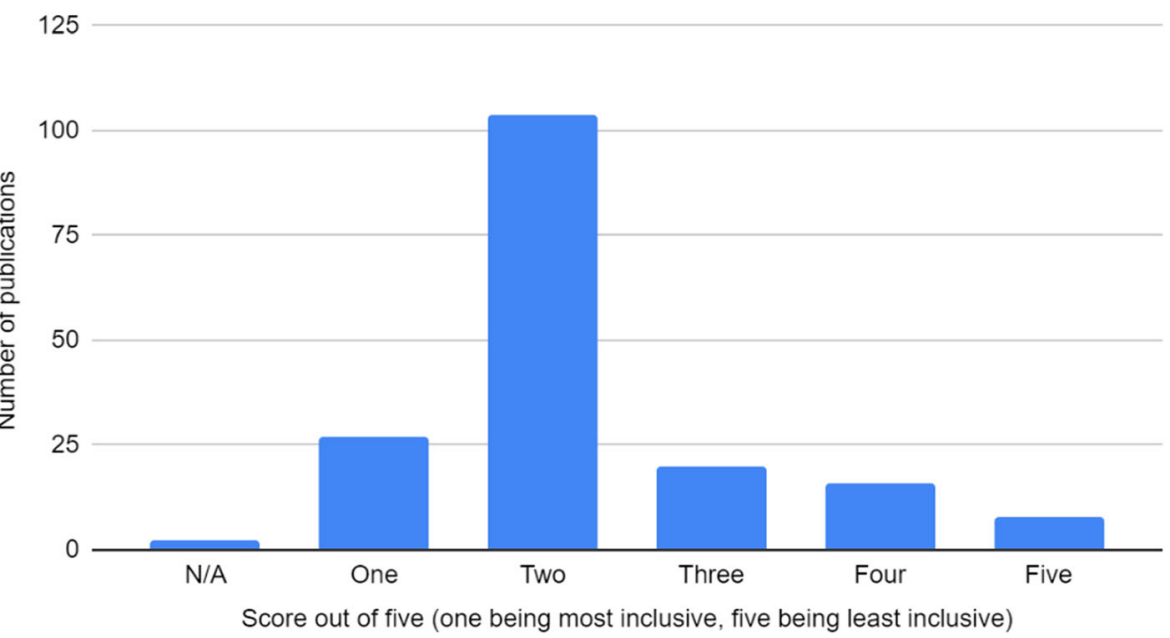

Fig. 5 Publications scored based on their degree of inclusivity of the term 'gender'

Given our purpose of determining the extent to which sex and gender are accounted for in the policy process, the authors met weekly for 2 months to discuss the findings of their respective readings of the extracted sources. The original themes were determined after reading 50\% of the extracted sources; these thematic results were confirmed and elaborated on further via the remaining sources: (1) synonymous use of gender and sex, with prioritization of gender; (2) common use of gender/ sex binaries; (3) current best practices in integrating sex and gender; (4) geographical variation in comprehensiveness, and; (4) timeliness, with documents published more recently being more comprehensive. The key findings have been summarized in Fig. 7.

\section{Synonymous use of gender and sex}

The vast majority of sources used sex and gender synonymously, often prioritizing the use of gender to describe both sex and gender. This was evident in the United Nations Women's Progress of the World's Women 2015-2016 report, in which the term gender was frequently used in reference to both "biological differences" and "socially-determined differences" [111]. In the few instances were sex was discussed, the term was similarly arbitrarily used in reference to both biological and social variables. Furthermore, the document made no distinction between the terms 'male/female' and 'men/women'. The terms are used entirely interchangeably, sometimes even within the same sentence, further alluding to the

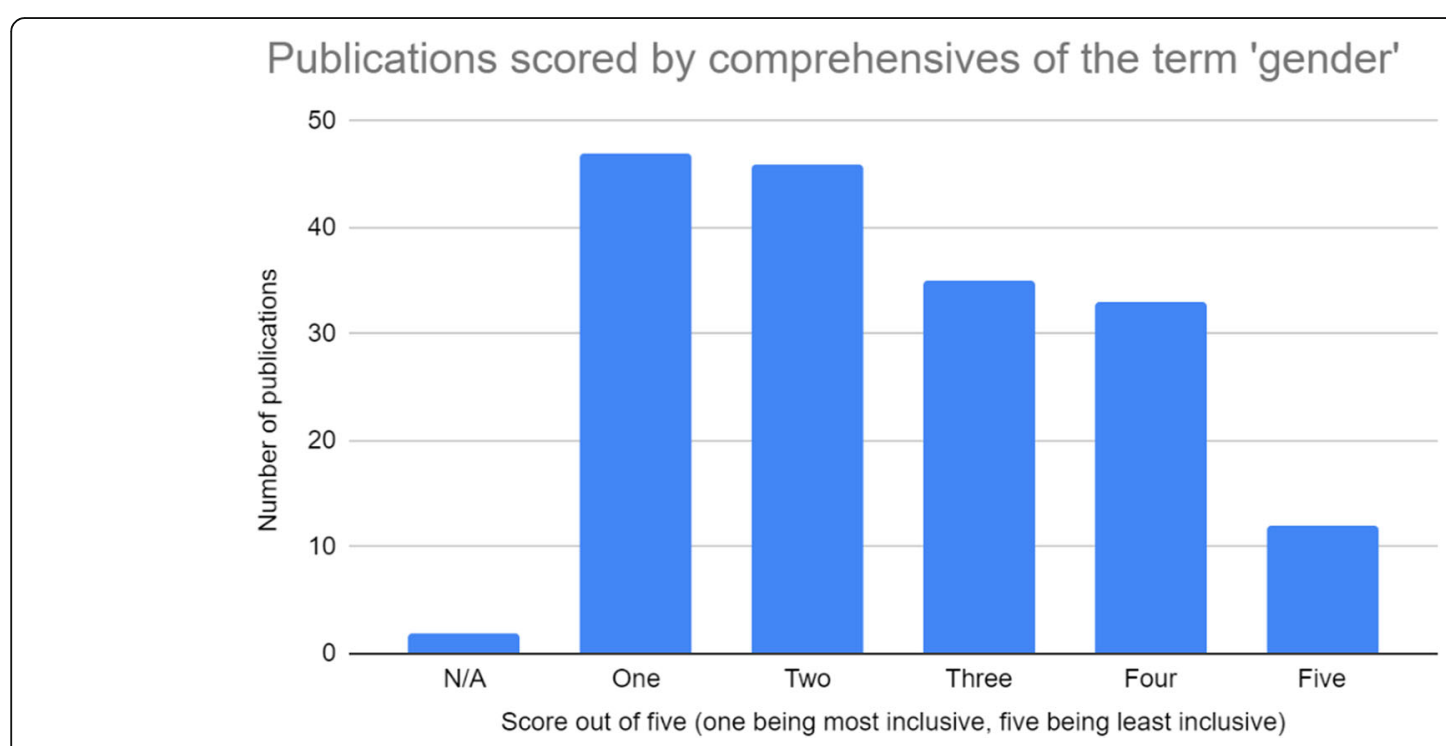

Fig. 6 Publications scored based on their comprehensiveness of the term 'gender' 


\begin{tabular}{|c|c|}
\hline Theme 1: Synonymous use of sex and gender & $\begin{array}{l}\text { Indicated high inclusivity/comprehensiveness (1 to 5): } \\
\text { - Clear differentiation of the terms 'sex' and 'gender' } \\
\text { - Consistent use of the terms 'sex' and 'gender' } \\
\text { Indicated low inclusivity/comprehensiveness (1 to 5): } \\
\text { - Poor differentiation of the terms 'sex' and 'gender' } \\
\text { - Interchangeable use of the terms 'sex' and 'gender', }\end{array}$ \\
\hline Theme 2: Common use of sex and gender binaries & $\begin{array}{l}\text { Indicated high inclusivity/comprehensiveness (1 to 5): } \\
-\quad \text { Acknowledgement of sex and gender identities outside of } \\
\text { a binary sex or gender framework } \\
\text { Indicated low inclusivity/comprehensiveness (1 to 5): } \\
\text { - } \quad \text { No acknowledgement of sex and gender identities } \\
\text { outside of a binary sex or gender framework }\end{array}$ \\
\hline Theme 3: Current best practices in integrating sex and gender & $\begin{array}{l}\text { Indicated high inclusivity/comprehensiveness (1 to 5): } \\
-\quad \text { Acknowledgement of the unique perspectives and } \\
\text { experiences of sex and gender minorities } \\
\text { Indicated low inclusivity/comprehensiveness }(1 \text { to 5): } \\
\text { - } \quad \text { No acknowledgement of the unique perspectives and } \\
\text { experiences of sex and gender minorities }\end{array}$ \\
\hline Theme 4: Geographical variation & $\begin{array}{l}\text { Indicated high inclusivity/comprehensiveness (1 to 5): } \\
-\quad \text { Sources created on a regional or national level } \\
\text { Indicated low inclusivity/comprehensiveness ( } 1 \text { to } 5) \text { : } \\
\quad \text { - Sources created on a multinational or international level }\end{array}$ \\
\hline Theme 5: Timeliness & $\begin{array}{l}\text { Indicated high inclusivity/comprehensiveness }(1 \text { to } 5) \text { : } \\
-\quad \text { Sources published within the last five years } \\
\text { Indicated low inclusivity/comprehensiveness ( } 1 \text { to } 5) \text { : } \\
\quad-\quad \text { Sources published prior to the last five years }\end{array}$ \\
\hline
\end{tabular}

Fig. 7 Summary of key findings relevant to each theme

document's conflation of sex and gender [111]. This suggests an inadequate understanding of the distinction between these two terms.

The synonymous use of gender and sex also suggests a very constrained interpretation of these terms, often exclusive to the binary male/female or men/women dichotomies. In the vast majority of documents, gender was operationalized in terms of this binary framework $(n=129)$. As a result, these documents often failed to consider the perspectives of individuals who do not conform to the traditional masculine or feminine gender norms. This suggests that transgender, genderqueer, and third gender individuals are frequently excluded from the decision-making processes outlined by these documents, in turn reducing the efficacy of these processes as they apply to these gender minorities. Sex, when discussed, was often operationalized in a similar binary framework $(n=70)$. This frequently resulted in a lack of consideration for certain groups, namely intersex individuals, who do not conform to the binary male/female framework of sex.

Related to this is the common use of sex-disaggregated data being used as a proxy for gender outcomes. Sexdisaggregated data was presented in many sources as evidence of gender inequities. In such cases, the terms sex and gender were often assumed to be synonymous, and no effort had been made to acknowledge how this discrepancy had been taken into account. For instance, in the Gender Mainstreaming in Practice handbook published by the United Nations Development Programme, the author states that "all indicators should be disaggregated by sex wherever possible [as] this helps identify the gender differentiated impact of our interventions" [15]. In this instance, no attempt is made to consider the degree to which sex-disaggregated data may be of relevance to gender-oriented strategies.

Several documents offered alternatives to using sexdisaggregated data as a proxy for gender variables. For instance, the Toolkit for a Gender-Responsive Process to Formulate and Implement National Adaptation Plans (NAPS) lists 'gender analyses' as a distinct measure which may be used to assess gender dynamics and inequities [156]. The Gender Mainstreaming Checklist for the Health Sector, published by the African Development Group, similarly advocated for the use of 'gender indicators' to measure gender-related changes over time [47].

\section{Common use of sex and gender binaries}

Related to the first theme, many sources used constrained definitions of sex and gender, which were often limited to a binary understanding. That is, populations were deemed to fit within one of two given categories, 
whether male/female in the case of sex, or women/men in the case of gender. Of the documents included in the scoping review, the majority used binary definitions of gender $(n=129)$ or sex $(n=153)$. As a result, populations which do not conform to the traditional, binary understanding of sex and gender were frequently excluded from consideration in these documents. The perspectives of intersex individuals were only considered alongside cis males and females in 22 of the documents, whereas the perspectives of transgender and gender diverse individuals were only alongside cis men and women in 41 of the documents.

Some plausible explanations for this include the relative under-representation of transgender populations in research in general [179], particularly outside of Canada and Northern Europe, the perceived difficulty of accounting for transgender populations in quantitative research [180, 181], and the widespread imposition of gender binaries during colonization, effectively erasing the strong pre-colonial histories of third gender and transgender populations in many Asian and South American countries [182, 183].

\section{Current best practices in integrating sex and gender}

Of the documents which identified transgender and gender diverse populations as a subject of interest in SGA+ $(n=29)$, only a subset $(n=11)$ did so in a truly inclusive and comprehensive way. While several of these papers explicitly focused on transgender populations as their primary subject of study [30,32, 38, 53, 92], some of the most inclusive and comprehensive papers approached transgender and gender diverse populations alongside cisgender populations as part of an overall approach to gender analysis. Articles that focused on HIV/AIDS or sexual violence, particularly within the global south, were typically more inclusive of transgender women as populations with higher exposures to risks associated with sexual violence and HIV/AIDS [33, 111, 149, 171], generally as a result of their over-representation within the commercial sex trade. Transgender men were rarely discussed except in the context of broader gender minorities, although some documents focusing on sexual and reproductive health note that this population is highly vulnerable to sexual violence $[111,149,184-186]$.

It is important to note that while many documents addressed binary transgender populations, representation of non-binary and third genders were typically ignored. This is important to note as many Indigenous cultures, particularly in the global south, had strong traditions of third genders and non-binary genders that pre-date colonization. Documents which recognized this [147, 149] were typically focused on or produced by scholars working within the global south. Indeed, the document which was assessed to have the most comprehensive and inclusive approach to sex and gender, and which recognized the experiences of transgender populations as existing within the broader context of gendered oppression, was focused on the gendered differences in experiences of public transit in Pakistan [147]. This document included the experiences of cisgender men and women on public transit but also focused on the experiences of transgender Pakistanis, many of whom identified as being hirja, a third gender which was present throughout the Indian subcontinent and South Asia prior to colonization. By considering hirja experiences alongside the experiences of cisgender women and men, this document engages deeply in a comprehensive and inclusive gender analysis which highlights the diverse experiences of transgender people in the context of broader gendered experiences of public transit.

\section{Geographical variation}

Given political structures and history, religious beliefs and cultural norms within particular societies across the world, certain geographical regions and nations were found to be comparatively more comprehensive and inclusive in their interpretation of sex and gender than others. For example, although there were comparatively fewer sources from, or representative of, countries within the regions of Southeast Asia and South America, those that were examined and which included a comprehensive approach to sex and gender were found to be more inclusive of non-binary and third-gender transgender populations $[53,149,171]$, while the documents from Western Europe and North America which included transgender populations typically highlighted the experiences of binary transgender men and women [28, 32]. It should be noted that a number of Canadian documents also included two-spirit populations [50, 92], a distinct difference from the United States and Western Europe. It is also important to note that while a number of papers $(n=29)$ were inclusive of transgender populations, very few $(n=8)$ included intersex populations, meaning that a number of the documents which took a comprehensive and inclusive approach to gender did not extend the same level of inclusivity to sex.

The extracted sources, in totality, illustrated that regional or nationally produced sources were more likely to have enhanced comprehensiveness when compared to those sources created by a grouping of nation states, such as those sources produced by the transnational organizations, for example. Documents produced for international bodies, particularly within the grey literature, typically defaulted to more conservative and less comprehensive approaches to sex and gender. The exception to this general trend was found in papers produced for International NGOs dedicated to sexual and reproductive health, which were more comprehensive $[149,171]$. 


\section{Timeliness}

The passage of time has proven to stretch the understanding of both sex and gender as distinctive continuums, rather than restrained categories. In contrast, many sources published in the early 2000s used a much more confined interpretation, with sex and gender being viewed as binary measures which were regarded to be interchangeable with one another. Sources more recently published in the last 5 years were more likely to be comprehensive and inclusive than those published closer to the beginning of the time period of concern. The majority of these recent sources were from the grey literature $(n=54)$, although several were found in the peerreviewed academic literature $(n=31)$. This reflects an expansion of knowledge and understanding of both sex and gender, and suggests a greater acceptance of sex and gender as unique continuums, and both as relevant axis' of diversity. The 'Gender Assessment Tool' of the International Planned Parenthood Federation, published in 2019, is illustrative of this [171]. The authors of the document clearly define gender as "a fluid concept that is present through all social life" which "is not biological or natural but is constructed from the images, messages and expectations we see around us", and emphasize that the concept is distinct from sex, which is said to consist of "biological features, such as male or female anatomy" [171]. If this trend were to continue, as expected, the passage of time will see an increase in comprehensibility and inclusivity of both sex and gender.

\section{Limitations}

Recognizing the rigorous search strategy informed by a university librarian, there are two limitations evident. Given the time-intense process of reading each document, each document was reviewed by only one of the four authors. Documents would have been more thoroughly reviewed if more than one author was involved, ideally providing a cross-check. Further, English-language sources were solely considered for inclusion. As a result, it is possible the review may have missed relevant documents written in other languages.

\section{Conclusion}

There has been a recognition by researchers and policymakers, both government and non-governmental national and international organizations, of the need to establish and promote sex and gender equality, especially with respect to accessing appropriate health opportunities. The objective of this scoping review was to determine the inclusivity and comprehensiveness of the use of sex and gender in health policymaking. The process consisted of a review of existing literature, both grey $(n=110)$ and academic $(n=65)$, to identify prior instances of the use of sex and gender in health policymaking. These were used to determine gaps and assess best practices. The results of the scoping review have shown that while the call to action has grown over the years, there has been a slow adoption to integrate a more comprehensive definition of sex and gender in health policymaking.

In order to lay a foundation for this study, there was a need to establish a definition and broad operationalization of the terms sex and gender. The distinction between these two terms is critical given our interest in developing an inclusive and comprehensive approach that fills the current gap in the assessment of sex and gender considerations in health policymaking. Certain themes emerged from the literature. First, while sex is defined as the genetic, physiological, and biological characteristics that distinguish males and females, and gender refers to the socially constructed characteristics that distinguish men and women, it was found that the vast majority of sources used the two terms synonymously, often prioritizing gender to describe both. This implied a narrow interpretation of these terms, leading to a simple binary view of women and men and, consequently, resulting in an inadequate understanding of each term's distinctiveness. Our study identified this as a major gap. In order to narrow or eliminate this gap, toolkits need to develop metrics that make the distinction between sex and gender and expand their definitions to be more inclusive of transgender and non binary lifestyles.

The second theme is closely related to the first. Our study was particular in reviewing the inclusivity and comprehensiveness of the definitions of sex and gender. Inclusivity was defined as the extent to which the paper took into account persons outside of the traditional simple binary view of women and men, as well as the heterogeneity of individuals beyond sex and gender. Comprehensiveness was measured by how consistently and accurately the terms were used in the publication. The study revealed that transgender and other gender diverse populations were rarely included in these publications. Although plausible explanations may be those of simple under representation of transgender populations in the research, and/or the colonizing impact of imposing a simple binary viewpoint, it still remains that in the timeframe from the year 2000 on, there were few publications that made the effort to include transgender and other gender diverse populations. Our study identified this as a secondary gap. In order to have the most holistic and inclusive health policy for all, there has to be the recognition that the definition of sex needs to be expanded to include transgender and non binary persons and that sex is not to be used synonymously with the 
term gender but is to be considered on its own merits and operationalized by metrics that take this into account.

Fourthly, it was found that certain geographical regions and nations were more inclusive and comprehensive in their interpretation of sex and gender. Regions of Southeast Asia and South America were more inclusive of non-binary and third-gender transgender populations, while papers from North America and Western Europe, which included transgender populations, typically only highlighted experiences of binary transgender men and women. That being said, there were several noteworthy exceptions to these regions, most notably in the documents from Canada and the Nordic Countries. It was noted that few publications included intersex populations. In any case, those papers that took a comprehensive and inclusive approach to gender did not usually extend that thoroughness to sex. Generally, regional and nationally produced sources were more comprehensive in their studies, while studies from international organizations were more conservative and less comprehensive in their approach to sex and gender. The limitation of only reviewing publications in English may have prevented a more expansive scoping review. The limitation of only reviewing publications in English may have prevented a more expansive scoping review. This limitation is more difficult to overcome without the ability to speak another language. However, it is possible to have articles translated from other countries to enhance the thoroughness of any future review. It is possible that greater strides have already been taken to have a more inclusive and comprehensive approach to health policy, but they are simply not available in the English language, and it behooves us to reach out to find out if better practices exist out there.

Finally, it was found that publications in the last 5 years were more inclusive and comprehensive of sex and gender than those published earlier. This indicates more recent awareness and understanding, as well as a comparative increase in knowledge regarding the acceptance and importance of expanding the inclusivity and comprehensiveness of sex and gender. This scoping review highlights the need for policymakers to: enhance their ability to better incorporate transgender and other diverse populations via a more inclusive and comprehensive understanding of sex and gender; develop a more holistic approach to health policymaking, and consequently; provide better health policymaking outcomes. This is critical if our health policies are to be inclusive of everyone they serve. A better understanding of the term sex can lead to a better ability to address the special needs of women, men, transgender and non binary persons, alike. This, with a better understanding of the term gender, will bring the balance necessary to make our health policy the most inclusive and comprehensive one it can be.

This paper, and many of the most comprehensive and inclusive articles, understands sex and gender as representing important determinants of health which must be understood in the context of other social determinants of health. Comprehensive and inclusive approaches to gender and sex often also considered the relevance of socioeconomic status, racial or ethnic identity, religion, age, and migration status, suggesting that a comprehensive approach to sex and gender also often entails a more comprehensive approach to other aspects of identity and health.

It is important to note that there are real-world consequences when policy documents fail to address sex and gender in a comprehensive and inclusive way. All of the papers which were assessed as failing to adequately operationalize comprehensive understandings of sex and gender failed to account for transgender, gender diverse, and intersex populations. This is meaningful: the erasure of transgender and gender diverse populations has been linked with poorer health outcomes for transgender patients $[179,180]$. Further, the failure to adequately distinguish between sex and gender has scientific implications beyond the political and social realms. Transgender women are often at a higher risk of HIV transmission due to their overrepresentation in the commercial sex trade, but studies on HIV transmission typically either exclude them from consideration or conflate them with men who have sex with men (MSM) [181]. This limits the ability of researchers and policymakers to understand the social and behavioural factors which increase HIV vulnerability among trans women and may lead to potential inadequacies in HIV prevention policies based on this research.

In summary, this scoping review revealed clear gaps in the inclusive and comprehensive incorporation of sex and gender in the development of health policy. It showcased the need for new standards, tools and strategies that could overcome these gaps. This scoping review has provided the foundation to inform a sex and gender inclusive toolkit for policymakers, which would better integrate sex and gender considerations in a more comprehensive and holistic approach to health policymaking. Following the methodological framework outlined in Day et al. (7), next steps need to be taken to implement the findings from this scoping review to develop metrics that policymakers can use to create best policy that best integrates sex and gender considerations. The next steps would follow those outlined in Day et al. (7). These steps include seeking input from select study participants (i.e. those involved in health policy development), by way of a questionnaire reviewing a draft set of metrics integrating sex and gender in health policy. The input will help 
refine the set of metrics and, ultimately increase the metric's credibility for use in the health policy field.

\section{Acknowledgements}

None.

\section{Authors' contributions}

All authors were involved in data analysis and collection. All authors were involved in writing, reading, and approving the final manuscript.

\section{Funding}

This research was funded by a grant received from the Canadian Institutes of Health Research (CIHR). The CIHR award number of this grant was HPW146001, under the title of "Mobilizing a Caregiver-Friendly Workplace Stand ard: A Partnership Approach". The Social Science and Humanities Research Council (SSHRC) funding reference number is 895-2018-4005.

\section{Availability of data and materials}

Data is available upon request from the corresponding author.

\section{Ethics approval and consent to participate}

This study received ethics approval from the McMaster Research Ethics Board through the McMaster Research Ethics Manager. Consent to participate was not applicable to this study, as no human participants were involved.

\section{Consent for publication}

Not applicable

\section{Competing interests}

The authors have no competing interests to declare.

\section{Received: 13 September 2020 Accepted: 17 February 2021}

Published online: 02 March 2021

\section{References}

1. Day S, Mason R, Tannenbaum C, Rochon PA. Essential metrics for assessing sex \& gender integration in health research proposals involving human participants. PLoS One. 2017;12(8):e0182812.

2. Short SE, Yang YC, Jenkins TM. Sex, gender, genetics, and health. Am J Public Health. 2013;103(S1):S93-101.

3. Jones T. Intersex studies: a systematic review of international health literature. SAGE Open. 2018;8(2):2158244017745577.

4. Doyal L. Sex, gender, and health: the need for a new approach. Bmj. 2001; 323(7320):1061-3

5. Xiong C, Biscardi M, Nalder E, Colantonio A. Sex and gender differences in caregiving burden experienced by family caregivers of persons with dementia: a systematic review protocol. BMJ Open. 2018;8(8):e022779.

6. Sharma N, Chakrabarti S, Grover S. Gender differences in caregiving among family-caregivers of people with mental illnesses. World J Psychiatry. 2016; $6(1): 7$

7. United Nations Economic Commission for Europe. Working party on regulatory cooperation and standardization policies. Geneva: UNESC; 2016. Report No.: ECE/SCTCS/WP.6/2016/3

8. Arksey H, O'Malley L. Scoping studies: towards a methodological framework. Int J Soc Res Methodol. 2005:8(1):19-32.

9. Peterson J, Pearce PF, Ferguson LA, Langford CA. Understanding scoping reviews: definition, purpose, and process. J Am Assoc Nurse Pract. 2017; 29(1):12-6.

10. Pham MT, Rajić A, Greig JD, Sargeant JM, Papadopoulos A, McEwen SA. A scoping review of scoping reviews: advancing the approach and enhancing the consistency. Res Synth Methods. 2014;5(4):371-85.

11. Aid A. Tool Kit on Gender Equality Results adn Indicators. Asian Development Bank; 2013

12. Quisumbing AR, Meinzen-Dick R, Raney TL, Croppenstedt A, Behrman JA, Peteman A. Gender in agriculture. Springer. 2014;102072:444.

13. Mkandawire E. Interpretations of gender and implications for policy: a case of Malawi's Nutrition policymaking process (Doctoral dissertation, University of Pretoria). 2018

14. Canadian International Development Agency. Accelerating change: resources for gender mainstreaming. CIDA: Gatineau; 2000. Available from: http://www.sice.oas.org/Genderandtrade/CIDA_Accchange-E.pdf
15. Neimanis A. Gender mainstreaming in practice: a handbook: UNDP RBEC; 2000

16. Schofield T, Connell RW, Walker L, Wood JF, Butland DL. Understanding men's health and illness: a gender-relations approach to policy, research, and practice. J Am Coll Heal. 2000;48(6):247-56.

17. Gomez EG. Gender equity and health policy reform in Latin America and the Caribbean. Committee For International Cooperation in National research in Demography (CICRED); 2002.

18. Hills M, Mullett J. Women-centred care: working collaboratively to develop gender inclusive health policy. Health Care Women Int. 2002;23(1):84-97.

19. Manual G. A practical guide for development policy makers and practitioners: DFID. Social Development Division; 2002.

20. Vlassoff C, Moreno CG. Placing gender at the centre of health programming: challenges and limitations. Soc Sci Med. 2002;54(11):1713-23.

21. Von Dach SW. Integrated mountain development: a question of gender mainstreaming. Mt Res Dev. 2002;22(3):236-9.

22. Farr V. Gender awareness in research and policy making: on the danger of further attacks in sub-Saharan Africa. Afr Secur Stud. 2003;12(1):116-9.

23. Reeves D, Greed C. Gender Equality and Plan Making: The Gender Mainstreaming Toolkit, with contributors, Linda Davies, Caroline Brown and Stephanie Duhr (London, RTPI). 2003. Final web version edited by C. Sheridan and D. Reeves for RTPI and available at www.rtpi.org.uk.

24. Auret D, Barrientos S. Participatory social auditing: a practical guide to developing a gender-sensitive approach; 2004.

25. Council of Europe. Gender mainstreaming: conceptual framework methodology and presentation of good practices - final report of activities of the Group of Specialists on Mainstreaming. Strasbourg: Council of Europe; 2004.

26. Hannan C. Gender mainstreaming: A key strategy for promoting gender equality at national level. In: UN-ESCAP high-level intergovernmental meeting to review regional implementation of the Beijing Platform for Action and its regional and global outcomes; 2004. p. 7-10

27. National Committee on the Advancement of Women Viet Nam. Gende mainstreaming guidelines in national policy formulation and implementation. Hanoi: National Committee on the Advancement of Women Viet Nam; 2004

28. Braithwaite M. Gender-sensitive and women friendly public policies: a comparative analysis of their progress and impact. Relatório Final do Projecto Equapol. 2005.

29. Moser C, Moser A. Gender mainstreaming since Beijing: a review of success and limitations in international institutions. Gend Dev. 2005;13(2):11-22.

30. Rodríguez-Madera S, Toro-Alfonso J. Gender as an obstacle in HIV/AIDS prevention: considerations for the development of HIV/AIDS prevention efforts for male-to-female transgenders. Int J Transgenderism. 2005;8(2-3): 113-22.

31. Schofield T, Goodwin S. Gender politics and public policy making: prospects for advancing gender equality. Polic Soc. 2005;24(4):25-44.

32. Samelius L, Wågberg E. Sexual orientation and gender identity issues in development. Sida; 2005.

33. Gideon J. Integrating gender interests into health policy. Dev Chang. 2006; 37(2):329-52.

34. Mehra R, Gupta GR. Gender mainstreaming: making it happen: International Center for Research on Women (ICRW); 2006.

35. Östlin P, Eckermann E, Mishra US, Nkowane M, Wallstam E. Gender and health promotion: A multisectoral policy approach. Health Promot Int. 2006; 21(suppl_1):25-35.

36. United Nations Chief Executives Board for Coordination. United Nations system-wide policy on gender equality and the empowerment of women: Focusing on results and impact: UNCEBC; 2006.

37. Wendt S, Lateef S, Schoeffel P, Asico MA, Guillermo M. Gender Checklist: Health: ADB; 2006. Report No.: 0248NP. Available from: http://hdl.handle. net/11540/2441

38. Hansson U, Hurley-Depret M, Fitzpatrick B. Equality mainstreaming: policy and practice for LGB people; 2007.

39. Keuken DG, Haafkens JA, Hellema MJ, Burgers JS, Moerman CJ. Incorporating a gender perspective into the development of clinical guidelines: a training course for guideline developers. Implement Sci. 2007; 2(1):1-7.

40. Niemanis A. Gender mainstreaming in practice: a toolkit. United Nations Development Programme: Regional Bureau for Europe and the CIS (UNDP RBEC); 2007. 
41. Ravindran TS, Kelkar-Khambete A. Women's health policies and programmes and gender mainstreaming in health policies, programmes and within the health sector institutions. Background paper prepared for the Women and Gender Equity Knowledge Network of the WHO Commission on Social Determinants of Health. 2007.

42. Agustín LR. Civil society participation in EU gender policy-making: framing strategies and institutional constraints. Parliam Aff. 2008;61(3):505-17.

43. Covington S, Bloom B. Gender-responsive program assessment. Washington, DC: National Institute of Corrections; 2008.

44. Goodwin R. Gender mainstreaming toolkit for water and sanitation actors: gender mainstreaming in the project cycle and within institutions. Nairobi: UN Habitat; 2008. Available from: https://mirror.unhabitat.org/downloads/ docs/2527_1_595415.pdf

45. Hankivsky O. Gender mainstreaming in Canada and Australia: a comparative analysis. Polic Soc. 2008;27(1):69-81.

46. United Nations High Commissioner for Refugees. UNHCR Handbook for the Protection of Women and Girls. Geneva: UN; 2008. p. 1. Available from: https://www.unhcr.org/4ad33d5a6.pdf

47. African Development Bank Group. Gender Mainstreaming Checklist for the Health Sector: AfDB; 2009. Available from: https://www.afdb.org/fileadmin/ uploads/afdb/Documents/Policy-Documents/Gender-health-chklistsunita-12-01-09\%20(2).pdf

48. African Union. Gender policy. Addis Ababa: AU; 2009

49. Malaza N. Gender in planning and urban development. London: Commonwealth Secretariat; 2009. p. 14. ISSN: 23102322 (online)

50. Mulé NJ, Ross LE, Deeprose B, Jackson BE, Daley A, Travers A, Moore D. Promoting LGBT health and wellbeing through inclusive policy development. Int J Equity Health. 2009;8(1):1-1.

51. Pan American Health Organization. Guide for analysis and monitoring of gender equity in health policies: WHO; 2009. Available from: https://www.pa ho.org/hq/dmdocuments/2009/Guide_Gender_equity_.pdf

52. Sriani A, Kawar M. Guidelines on gender in employment policies: ILO; 2009.

53. Winter S. Cultural considerations for the World Professional Association for Transgender Health's standards of care: the Asian perspective. Int J Transgenderism. 2009;11(1):19-41.

54. World Health Organization. Integrating gender into HIV/AIDS programmes in the health sector: tool to improve responsiveness to women's needs. 2009

55. Canadian Centre on Substance Abuse. Bringing gender and diversity analysis to our work: a checklist: CCSA; 2010. Available from: https://www. ccsa.ca/sites/default/files/2019-05/SexDiversityChecklist.pdf

56. Debusscher P. Gender mainstreaming in European commission development policy in Asia: a transformative tool? Asian J Women's Stud. 2010;16(3):80-111.

57. Gender Section of the OSCE. Gender matters in the OSCE: CD toolkit. Ed Seftaoui J. Vienna: OSCE; 2010.

58. Greyson DL, Becu AR, Morgan SG. Sex, drugs and gender roles: mapping the use of sex and gender based analysis in pharmaceutical policy research. Int J Equity Health. 2010;9(1):26.

59. Holmes R, Jones N. How to design and implement gender-sensitive social protection programmes: ODI; 2010. Available from: https://www.odi.org/ sites/odi.org.uk/files/odi-assets/publications-opinion-files/6262.pdf

60. International Labour Organization. Gender mainstreaming strategies in decent work promotion: programming tools; GEMS toolkit. Bangkok: ILO. 2010. ISBN: 9789221238706. Available from: https://www.lo.org/wcmsp5/ groups/public/\%2D\%2D-asia/\%2D\%2D-ro-bangkok/\%2D\%2D-sro-bangkok/ documents/publication/wcms_143849.pdf.

61. Mannell J. Gender mainstreaming practice: considerations for HIV/AIDS community organisations. AIDS Care. 2010;22(sup2):1613-9.

62. Richardson N. 'The "buck" stops with me'-reconciling men's lay conceptualisations of responsibility for health with men's health policy. Health Sociol Rev. 2010;19(4):419-36.

63. United Nations Economic Commission for Europe. Developing gender statistics: a practical tool. Geneva: UN; 2010. Available from: http://www. unece.org/fileadmin/DAM/stats/publications/Developing_Gender_Sta tistics.pdf

64. World Health Organization. Checklist for assessing the gender responsiveness of sexual and reproductive health policies: pilot document for adaptation to national contexts. Copenhagen: WHO; 2010. p. 6.

65. Ghanem $\mathrm{H}$. The state of food and agriculture: women in agriculture: closing the gender gap for development. Rome: FAO; 2011.
66. Mercy Corps. BRIDGE \& gender mainstreaming: a guide for program staff. 2011.

67. Office of the United Nations High Commissioner for Human Rights. Gender equality policy. Geneva: OHCHR; 2011. Available from: https://www2.ohchr. org/english/issues/women/docs/genderequalitypolicy_september2011.pdf

68. World Health Organization. Gender mainstreaming for health managers: a practical approach: WHO; 2011. ISBN: 978-92-4-150107-1

69. World Health Organization. Human rights and gender equality in health sector strategies: how to assess policy coherence: WHO; 2011.

70. CARE International Gender Network. Good practices framework: gender analysis: CARE; 2012. Available from: https://www.care.org.au/wp-content/ uploads/2015/02/Good-Practices-Brief.pdf

71. CIHR Institute of Gender and Health. What a difference sex and gender make: a gender, sex and health research casebook. Ottawa: CIHR; 2012. Cat. No.: MR21-164/2012E-PDF. Available from: https://cihr-irsc.gc.ca/e/ documents/What_a_Difference_Sex_and_Gender_Make-en.pdf

72. East African Community. Guidelines and checklists for gende mainstreaming in EAC organs and institutions. Arusha: EAC; 2012. Available from: https://eassi.org/wp-content/uploads/2019/07/EAC-GENDERGUIDELINES-AND-CHECKLISTS.pdf

73. European Institute for Gender Equality. European conference: advancing gender training to support effective gender mainstreaming. Luxembourg: Publications Office of the European Union; 2012. ISBN: 978-92-9218-014-0

74. Van Eerdewijk A, Dubel I. Substantive gender mainstreaming and the missing middle: a view from Dutch development agencies. Gend Dev. 2012; 20(3):491-504

75. KIT, Agri-ProFocus, IIRR. Challenging chains to change: gender equity in agricultural value chain development. Amsterdam: KIT Publishers; 2012. ISBN: 978-94-6022-212-2

76. Kuhlmann E, Annandale E. Mainstreaming gender into healthcare: a scoping exercise into policy transfer in England and Germany. Curr Sociol. 2012; 60(4):551-68.

77. Lombardo E, Meier P, Verloo M. Policymaking and gender; 2012. https://doi. org/10.5278/freia.70824168.

78. McGill E, Lateef S, Alonzo-Calalay FMB. Gender tool kit: public sector management. Mandaluyong City: ADB; 2012. ISBN: 978-92-9092-749-5. Available from: https://www.adb.org/sites/default/files/institutionaldocument/33643/files/gender-tool-kit.pdf

79. Meyers L, Jones L. Gender analysis, assessment and audit manual and toolkit: ACDINOCA; 2012.

80. Richardson N, Smith JA. National men's health policies in Ireland and Australia: what are the challenges associated with transitioning from development to implementation? Public Health. 2011;125(7):424-32.

81. Rudaz G, Debarbieux B. 'Mountain women': silent contributors to the global agenda for sustainable mountain development. Gend Place Cult. 2012;19(5): 615-34.

82. Security policy and legislation: Formulating gender-responsive FNS policies. FAO. 2012. Available from: http://www.fao.org/elearning/Course/FG/en/ pdf/1237_text_only_1237.pdf

83. UNOCHA Policy Development and Studies Branch. OCHA gender toolkit: tools to help OCHA address gender equality: UN; 2012. Available from: https://www.unocha.org/sites/dms/Documents/GenderToolkit1_121205_5_ ver7.pdf

84. Bergin M, Wells JS, Owen S. Towards a gendered perspective for Irish mental health policy and service provision. J Ment Health. 2013;22(4): 350-60.

85. Department of Justice and Equality of Ireland. Towards Gender Parity in Decision-Making in Ireland: An Initiative of the Women's National Strategy 2007-2016: Government of Ireland; 2013. Available from: http://www.justice. ie/en/JELR/FINALTowards\%20Gender\%20Parity.pdf/Files/FINALTowards\%2 OGender\%20Parity.pdf

86. International Labour Organization. 10 Keys for gender sensitive OSH practice - Guidelines for gender mainstreaming in occupational safety and health. Geneva: ILO. 2013. ISBN: 978-92-2-127069-0. Available form: https:// www.ilo.org/wcmsp5/groups/public/\%2D\%2D-ed_protect/\%2D\%2D-protra v/\%2D\%2D-safework/documents/publication/wcms_324653.pdf.

87. Kirton RM. Gender, trade and public procurement policy: Kenya, India, Australia, Jamaica: Ed. Zatlokal B. Commonwealth Secretariat; 2013. Available from: https://thecommonwealth.org/sites/default/files/newsitems/documents/Gender\%20Trade\%20and\%20Public\%20Procurement\%2 OPolicy.pdf 
88. Alston M. Gender mainstreaming and climate change. In: Women's studies international forum, vol. 47. Pergamon; 2014. p. 287-94.

89. Bamberger M, Segone M, Reddy S. National evaluation policies for sustainable and equitable development: How to integrate gender equality and social equity in national evaluation policies and systems: EvalPartner; 2014. Available from: https://www.evalpartners.org/sites/default/files/documents/evalgender/ NationalEvaluationPolicies_web-single-color\%281\%29.pdf

90. Holvoet N, Inberg L. Gender sensitivity of sub-Saharan Africa National Adaptation Programmes of action: findings from a desk review of 31 countries. Clim Dev. 2014;6(3):266-76.

91. Interagency Gender Working Group. Handout: IGWG gender integration continuum categories. 2014.

92. Mulé NJ, Smith M. Invisible populations: LGBTQ people and federal health policy in Canada. Can Public Adm. 2014;57(2):234-55.

93. Organisation for Economic Co-operation and Development. Women, government and policy making in OECD countries: fostering diversity for inclusive growth: OECD; 2014. ISBN: 9789264210745

94. Schmitt M. Gender awareness in European alpine protected-area management: achievements, shortcomings, and the way forward. Mt Res Dev. 2014;34(3):291-6.

95. Shabib D, Khan S. Gender-sensitive adaptation policy-making in Bangladesh: status and ways forward for improved mainstreaming. Clim Dev. 2014;6(4): 329-35.

96. UN Women. Gender mainstreaming in development programming: UN Women; 2014

97. Vinas MC. Gender and policy toolkit: increasing the impact of action against hunger's work through gender equality programming. Action Against Hunger Int. 2014; Available from: https://actionagainsthunger.ca/cms/wpcontent/uploadGENDER\%20POLICY\%20AND\%20TOOLKIT\%20INCREASING\%2 OTHE\%20IMPACT\%20OF\%20ACTION\%20AGAINST\%20HUNGER\%E2\%80\% 995\%20WORK\%20THROUGH\%20GENDER\%20EQUALITY\%20PROGRA MMING/2018/08/Action-Against-Hunger-Gender-Policy-EN.pdf.

98. Bustelo M, Espinosa J, Faúndez A, Weinstein M. Guide to including a gender perspective in VOPEs: innovating to improve institutional capacities. Eur Eval Soc. 2015;28.

99. European Bank for Reconstruction and Development. The EBRD's strategy for the promotion of gender equality 2016-2020. London: EBRD; 2015.

100. Kuhlmann E, Annandale E. Gender and healthcare policy. In: The Palgrave international handbook of healthcare policy and governance. London: Palgrave Macmillan; 2015. p. 578-96.

101. Nelson G. Gender-responsive national communications toolkit. New York: UNDP; 2015

102. Organisation for Economic Co-operation and Development. OECD toolkit for mainstreaming and implementing gender equality: implementing the 2015 OECD recommendation on gender equality in public life: OECD; 2015. Available from: https://www.oecd.org/gov/toolkit-for-mainstreaming-andimplementing-gender-equality.pdf

103. Panisello ML, Pastor I. Health with equality: a proposal for the incorporation of the gender perspective in health care systems. Cien Saude Colet. 2015;20: 1555-63.

104. Swedish International Development Cooperation Agency. SIDA gender tool box. Stockholm: Sida; 2015. Available from: https://www.sida.se/contenta ssets/3a820dbd152f4fca98bacde8a8101e15/gender-tool-mainstreaming.pdf

105. Council of Europe. Achieving gender mainstreaming in all policies and measures: CoE; 2016. Ref. No.: 031316GBR. Available from: https://edoc.coe. int/en/gender-equality/6932-achieving-gender-mainstreaming-in-allpolicies-and-measures.html

106. Day S, Mason R, Lagosky S, Rochon PA. Integrating and evaluating sex and gender in health research. Health Res Policy Syst. 2016;14(1):75.

107. European Institute for Gender Equality. Gender equality training: gender mainstreaming toolkit. Vilnius: EIGE; 2016. ISBN: 978-92-9493-262-4

108. Hartmann M, Khosla R, Krishnan S, George A, Gruskin S, Amin A. How are gender equality and human rights interventions included in sexual and reproductive health programmes and policies: a systematic review of existing research foci and gaps. PLoS One. 2016;11(12):e0167542.

109. Kodama T, Ruckstuhl SM, Nguyen HM, Wilson C, Ignacio DR, Brown GM, Jacob KH. Toolkit for mainstreaming gender in water operations: The World Bank; 2016.

110. Scothern A, Brislane J. Implementing gender minimum standards: approaches, tools and lessons from the Solomon Islands NGO Partnership Agreement (SINPA). [internet]. Melbourne: IWDA; 2016. Available from: https://iwda.org.au/assets/files/ImplementingSINPAGenderMinStnds_F.pdf
111. Sen G. Progress of the world's women 2015-2016: transforming economies, realizing rights. Glob Soc Policy. 2016;16(1):94-6.

112. United Nations High Commissioner for Refugees. UNHCR Review of Gender Equality in Operations: UN; 2016. Available from: https://www. unhcr.org/protection/women/57f3b9a74/unhcr-review-gender-equalityoperations-2016.htm

113. Van Aelst K, Holvoet N. Intersections of gender and marital status in accessing climate change adaptation: evidence from rural Tanzania. World Dev. 2016;79:40-50.

114. Women With Disabilities Australia. Human Rights Toolkit: For Women and Girls with Disability. Hobart: WWDA; 2016. p. 1. ISBN: 978-0-9585269-9-9. Available from: http://wwda.org.au/wp-content/uploads/2016/10/WWDAHuman-Rights-Toolkit-Final.pdf

115. Women With Disabilities Australia (WWDA). Report: WWDA National Forum for Women and Girls with Disability: Proceedings and Outcomes. Hobart: WWDA; 2016. ISBN: 978-0-9775305-4-0

116. Working Party on Regulatory Cooperation and Standardization Policies. Twenty-sixth Session of the Working Party on Regulatory Cooperation and Standardization Policies (WP.6). Geneva: UN; 2016. Available from: https:// www.unece.org/wp6-26thsession.html

117. Alexander S, Hayes S. Viewing health policy through a gender lens: highlights from several US communities. Womens Health Issues. 2017;27:S2-5.

118. Avakyan Y, Bachan K, Davis VR, Fish K, Getman C, Romah L, Saggers M, Tabaj K, Williamson J, and Young E. Minimum Standards for Mainstreaming Gender Equality. FHI 360. 2017. Available from: https://www.fhi360.org/sites/ default/files/media/documents/minimum-standards-mainstreaming-genderequality.pdf.

119. Bacchi C. Policies as gendering practices: re-viewing categorical distinctions. J Women Polit Policy. 2017;38(1):20-41.

120. Bustelo M. Evaluation from a gender+ perspective as a key element for (re) gendering the policymaking process. J Women Polit Policy. 2017; 38(1):84-101.

121. Cairns MR, Workman CL, Tandon I. Gender mainstreaming and water development projects: analyzing unexpected enviro-social impacts in Bolivia, India, and Lesotho. Gend Place Cult. 2017;24(3):325-42.

122. Cooke M, Waite N, Cook K, Milne E, Chang F, McCarthy L, Sproule B. Incorporating sex, gender and vulnerable populations in a large multisite health research programme: the Ontario pharmacy evidence network as a case study. Health Rese Policy Syst. 2017;15(1):1-9.

123. Equal Measures 2030. Policymakers and gender equality: what they know and how they know it: EM2030; 2017.

124. Gold Standard. Gold Standard Gender Equality Guidelines \& Requirements: Gold Standard; 2017. Available from: https://www.goldstandard.org/sites/ default/files/documents/gs_gender_equality_guidelines_consultation.pdf

125. Green Climate Fund. Mainstreaming gender in Green Climate Fund projects: A practical manual to support the integration of gender equality in climate change interventions and climate finance. Incheon: GCF; 2017. p. 1. Available from: https://www.greenclimate.fund/sites/default/files/document/ guidelines-gcf-toolkit-mainstreaming-gender_0.pdf

126. loannides I. EU gender action plan 2016-2020 at year one: European implementation assessment. Study. European Parliamentary Research Service, European Parliament, Brussels; 2017.

127. Lombardo E, Meier P, Verloo M. Policymaking from a gender+ equality perspective. J Women Polit Policy. 2017;38(1):1-9.

128. Ministry of Business, Enterprise and Cooperatives of Mauritius. Gender Policy Statement: Government of Mauritius; 2017. Available from: http://enterbusiness. govmu.org/English/Documents/Gender\%20Policy\%20Statement.pdf

129. Multilateral Investment Fund. Toolkit for Mainstreaming Gender in MIF Projects. Inter-American Development Bank. 2017.

130. Nyamhanga T, Frumence G, Simba D. Prevention of mother to child transmission of HIV in Tanzania: assessing gender mainstreaming on paper and in practice. Health Policy Plan. 2017;32(suppl_5):v22-30.

131. Organisation for Economic Co-operation and Development Staff. The pursuit of gender equality: An uphill battle: OECD; 2017.

132. Pontes M, Barraja M, Wofford D, Rodehau C. Gender Equality in Codes of Conduct Guidance. BSR; 2017.

133. Tannenbaum C, Clow B, Haworth-Brockman M, Voss P. Sex and gender considerations in Canadian clinical practice guidelines: a systematic review. CMAJ Open. 2017;5(1):E66

134. Thankur D, Potter $L$. REACT with gender-responsive ICT policy: the key to connecting the next 4 billion. World Wide Web Foundation; 2017. 
135. United Nations Economic Commission for Europe. First meeting of the initiative for Gender-responsive standards under the auspices of the "Working Party on Regulatory Cooperation and Standardization Policies". Geneva: ITC; 2017.

136. Zhang ZH. Research on the Strategy of Promoting Gender Mainstreaming Effectively. In: 2017 2nd International Conference on Humanities and Social Science (HSS 2017): Atlantis Press; 2017.

137. Canadian Institutes of Health Research. Science is better with sex and gender: Strategic Plan 2018-2023. Ottawa: CIHR; 2018.

138. Guven P, Nicol S. Gender equality in Canada: mainstreaming, governance and budgeting: OECD; 2018.

139. Hankivsky O, Mussell L. Gender-based analysis plus in Canada: problems and possibilities of integrating intersectionality. Can Public Policy. 2018;44(4): 303-16.

140. Hennebry JL. The global compact for migration: from gender-rhetoric to gender-responsive? Glob Soc Policy. 2018;18(3):332-8.

141. International Gender Champions Representation Impact Group. GenderResponsive Assemblies: An Agenda for Concrete Action: International Gender Champions; 2018. Available from: https://s3.eu-west-2.amazonaws. com/igc-production/files/ODuhCKlqcARafvf2Qb4UXT3eyuB7_DFg.pdf

142. Kabir F. Towards a more gender-inclusive climate change policy. In: Handbook of research on women's issues and rights in the developing world: IGI Global; 2018. p. 354-69.

143. Ministry of Construction and Urban Development of Mongolia. The Construction and Urban Development Sector: Gender-Responsive Policy (2018-2025): Ulaanbaatar: Government of Mongolia; 2018. Available from: https://www.gender.gov.mn/uploads/books/attach/27.pdf

144. Mkandawire E, Hendriks SL, Mkandawire-Vahlmu L. A gender assessment of Malawi's national nutrition policy and strategic plan 2007-2012. Dev Policy Rev. 2018:36:0634-56.

145. Nutrition International. Integrating Gender Equality into Technical Assistance: Nutrition International; 2018. Available from: https://www. nutritionintl.org/content/user_files/2018/12/Gender-Equality-Checklist-TAproviders-2018-11-20.pdf

146. Office of the Inspector General. Guidance for Addressing Gender in Evaluations: IOM; 2018. Available from: https://www.iom.int/sites/default/ files/about-iom/evaluation/iom-gender-and-evaluation-guidance-2018.pdf

147. Panjwani N. Mainstreaming Gender in Karăchï's Public Transport Policy. Eur J Sustainable Dev. 2018;7(1):355.

148. Schiebinger $L$, Klinge I. Gendered innovation in health and medicine. In: Sex-specific analysis of cardiovascular function. Cham: Springer; 2018. p. 643-54.

149. UNAIDS. UNAIDS Gender Assessment Tool: Towards a gendertransformative HIV response. Geneva: UNAID; 2018. Available from: https:// www.unaids.org/sites/default/files/media_asset/unaids-gender-assessmenttool_en.pdf

150. UNICEF Regional Office for South Asia. Gender equality and rights: gender responsive communication for development: guidance, tools, and resources. Kathmandu: UNICEF South Asia; 2018. Available from: https://www.unicef. org/rosa/media/1786/file

151. UNICEF Regional Office for South Asia. Gender Toolkit: Integrating Gender in Programming for Every Child in South Asia: UNICEF South Asia; 2018. Available from: https://www.unicef.org/rosa/sites/unicef.org.rosa/files/201 8-12/Gender\%20Toolkit\%20Integrating\%20Gender\%20in\%20Progra mming\%20for\%20Every\%20Child\%20UNICEF\%20South\%20Asia\%202018.pdf

152. United Nations Economic Commission for Europe. Declaration for Gender Responsive Standards and Standards Development. Geneva: UN; 2018. ECE/ CTCS/WP.6/2018/6/Rev.1. Available from: https://www.unece.org/fileadmin/ DAM/trade/wp6/AreasOfWork/GenderInitiative/UNECEGenderDeclaration_ English.pdf

153. United Nations Economic Commission for Europe. Recommendations on Regulatory Cooperation and Standardization Policies: Revised Edition: UNECE; 2018. Available from: https://www.unece.org/fileadmin/DAM/trade/ wp6/Recommendations/WP6_Recommendations_E_2018.pdf

154. Women Engage for a Common Future. The gender impact assessment and monitoring tool. München: WECF; 2018. Available from: https://www.wecf. org/wp-content/uploads/2019/01/FINAL-GIM-Tool-Jan-19.pdf

155. Ciccia R, Lombardo E. Care policies in practice: how discourse matters for policy implementation; 2019.

156. Dazé A, Church C. Toolkit for a Gender-Responsive Process to Formulate and Implement National Adaptation Plans (NAPs):
Supplement to the UNFCCC Technical Guidelines for the NAP Process Winnipeg: International Institute for Sustainable Development; 2019. Available from: https://www4.unfccc.int/sites/NAPC/Documents/ Supplements/NAPGenderToolkit2019.pdf

157. European Partnership for Democracy. Women in Policy-Making: EPD; 2019.

158. Hasan MR, Nasreen M, Chowdhury MA. Gender-inclusive disaster management policy in Bangladesh: A content analysis of national and international regulatory frameworks. Int J Disaster Risk Reduction. 2019;41: 101324.

159. Jachia L. Standards \& gender equality: UN; 2019.

160. Mersha AA, van Laerhoven F. Gender and climate policy: a discursive institutional analysis of Ethiopia's climate resilient strategy. Reg Environ Chang. 2019;19(2):429-40.

161. Morris E, Greene J, Healey VM. Blueprint Guide for Creating Gender-Sensitive Energy Policies. Golden: National Renewable Energy Lab (NREL); 2019.

162. Organisation for Economic Co-operation and Development Staff. SIGI 2019 global report: transforming challenges into opportunities: OECD; 2019. ISBN: 9789264108905

163. Portal A, Vestfjarða H, Íslands L, Norðursins R, Rif R, Stefánssonar SV, Íslands V, á Blönduósi P, Pingeyinga P, í Nuuk Al, Music AT. Gender Equality. Corporate governance. 2019

164. Regensteiner JG, Libby AM, Huxley R, Clayton JA. Integrating sex and gender considerations in research: educating the scientific workforce. Lancet Diabetes Endocrinol. 2019;7(4):248-50.

165. Sexsmith K. Leveraging voluntary sustainability standards for gender equality and women's empowerment in agriculture: a guide for development organizations based on the sustainable development goals: IISD; 2019.

166. Standards Council of Canada. Gender and Standardization Strategy: 20192025 Action plan for gender responsive standards and gender balance in standards development. Ottawa: SCC; 2019. Available from: https://www.scc. ca/en/system/files/publications/SCC_Gender-and-Standardization-Strategy-2 019-2025_FINAL_EN.pdf

167. Tannenbaum C, Norris CM, McMurtry MS. Sex-specific considerations in guidelines generation and application. Can J Cardiol. 2019;35(5):598-605

168. United Nations Conference on Trade and Development. Making Trade Policies Gender-Responsive: Data Requirements, Methodological Developments and Challenges. Geneva: UN; 2019. UN Symbol: UNCTAD/ DITC/2019/1

169. United Nations Economic Commission for Europe. Gender Responsive Standards: UN; 2019. ISBN: 978-92-1-117202-7

170. West African Quality System Programme. The gender dimension of standards: WAQSP; 2019. Available from: https://www.unido.org/sites/defa ult/files/files/2019-03/UNIDO_Flyer_Standardization.pdf

171. Wilder R. Gender Equality Toolkit for IPPF Member Associations: Gender Assessment Tool: IPPF; 2019. Available from: https://www.ippf.org/sites/defa ult/files/2020-05/Gender\%20assessment\%20toolkit\%20English_0.pdf

172. Yakerson A. Women in clinical trials: a review of policy development and health equity in the Canadian context. Int J Equity Health. 2019;18(1):56.

173. Ampaire EL, Acosta M, Huyer S, Kigonya R, Muchunguzi P, Muna R, Jassogne L. Gender in climate change, agriculture, and natural resource policies: insights from East Africa. Clim Chang. 2020;158(1):43-60.

174. Lau JD. Three lessons for gender equity in biodiversity conservation. Conserv Biol. 2020

175. Organisation for Economic Co-operation and Development Staff. Working Party on Gender Mainstreaming and Governance: Towards a Gendersensitive Framework for Sound Public Governance. Paris: OECD; 2020. Available from: https://www.cig.gov.pt/wp-content/uploads/2020/02/GOVPGC-GMG2020-DRAFT-Towards-gender-sensitive-framework.pdf

176. Pla-Julián I, Guevara S. Mainstreaming gender and sustainability jointly: a case study from a local government in Spain. Local Environ. 2020;25(3):258-71.

177. Schmidt EK, Graversen EK. Developing a conceptual evaluation framework for gender equality interventions in research and innovation. Eval Program Plann. 2020; 79:101750

178. Shawar YR, Shiffman J. Political challenges to prioritizing gender in global health organisations. J Glob Health. 2020;10(1)

179. Friedrich C, Filippelli A. The transgender lens is underrepresented and overlooked in transgender health research to the detriment of the population it seeks to serve. J Women's Health. 2019;28(2):111. https:/doi.org/10.1089/jwh.2018.7646.

180. Bauer GR, Hammond R, Travers R, Kaay M, Hohenadel K, Boyce M. "I don't think this is theoretical; this is our lives": how erasure impacts health care 
for transgender people. J Assoc Nurses AIDS Care. 2009;22(5):348-61. https://doi.org/10.1016/j.jana.2009.07.004.

181. Henderson ER, Blosnich JR, Herman JL, Meyer IH. Considerations on sampling in transgender health disparities research. LGBT Health. 2019;6(6) https://doi.org/10.1089/lgbt.2019.0069.

182. Hunt S. Embodying self-determination: beyond the gender binary. In: Greenwood M, de Leeuw S, Lindsay NM, editors. Determinants of indigenous peoples' health, second edition: beyond the social. Toronto: Canadian Scholars' Press; 2018. p. 104-19.

183. Lugones M. Heterosexualism and the colonial/modern gender system. Hypatia. 2009;22(1):186-219 https:/doi.org/10.1111/j.1527-2001.2007.tb01156.x.

184. Du Bois SN, Yoder W, Guy AA, Manser K, Ramos S. Examining associations between state-level transgender policies and transgender health. Transgender Health. 2018;3(1).

185. Poteat T, German D, Flynn C. The Conflation of gender and sex: Gaps and opportunities in HIV data among transgender women and MSM. Glob Public Health. 2016;11(7-8).

186. Clayton J, Tannenbaum C. Reporting Sex, Gender, or Both in Clinical Research? JAMA. 2016;316(18):1863-4.

\section{Publisher's Note}

Springer Nature remains neutral with regard to jurisdictional claims in published maps and institutional affiliations.

Ready to submit your research? Choose BMC and benefit from:

- fast, convenient online submission

- thorough peer review by experienced researchers in your field

- rapid publication on acceptance

- support for research data, including large and complex data types

- gold Open Access which fosters wider collaboration and increased citations

- maximum visibility for your research: over $100 \mathrm{M}$ website views per year

At BMC, research is always in progress.

Learn more biomedcentral.com/submissions 